\title{
Pore Morphology of Lotus-type Porous Silver Fabricated by Gasar Process in Oxygen Atmosphere
}

\author{
Liang Juan ${ }^{1}, \quad$ Jin Qinglin', $\quad$ Yang Tianwu ${ }^{1}, \quad$ Li Zaijiu ${ }^{2}, \quad$ Xie Ming $^{2}$ \\ ${ }^{1}$ Kunming University of Science and Technology, Kunming 650093, China; ${ }^{2}$ Kunming Institute of Precious Metals, Kunming 650106, \\ China
}

\begin{abstract}
Directional solidification of metal/gas eutectic (Gasar) is a novel process for fabricating porous metals with oriented pores parallel to the solidification direction. Lotus-type porous silver samples with different porosities were fabricated by Gasar apparatus under pure oxygen atmosphere. The effects of gas pressure on porosity, pore nucleation, pore size and distribution were investigated. Results show that the porosity and the pore size in the lotus-type porous silver are significantly affected by the oxygen pressure. The porosity increases with the increasing of oxygen pressure, and the average pore diameter decreases with the increasing of oxygen pressure.
\end{abstract}

Key words: lotus-type; eutectic solidification; porous silver; oxygen; porosity

Porous and foamed metallic materials have become an attractive research field both from a scientific viewpoint and the prospect of industrial applications because they exhibit many unusual combinations of physical and mechanical properties, such as impact energy absorption capacity, air and water permeability, unusual acoustic energy absorption ability, and lower thermal conductivity. Various fabrication methods for porous materials have been developed. They include the foaming method with gas bubbling, the vapor deposition of metal onto polyurethane foam precursor, the powder sintering method and so on ${ }^{[1]}$. Generally, the spatial pore distribution in the porous metals fabricated by these methods is random. To solve the above problem, Shapovalov et al ${ }^{[2]}$ put forward a new method for fabrication of porous metal-gas eutectic directional solidification (Gasar ${ }^{[3]}$ ) in the United States in 1993. The porous materials fabricated by this method look like lotus roots, so they often have been called as lotus-type porous metals ${ }^{[4]}$. Generally, the mechanical properties of the lotus-type porous metals are superior to those of porous metals fabricated by foaming methods ${ }^{[5,6]}$.
Porous silver is an ideal catalyst in the oil and chemical industry. Porous silver can be fabricated by electro-deposition, cathode sputtering, and gas phase evaporation deposition ${ }^{[7]}$. However, the porous silver fabricated by these methods has shortcomings like poor strength and toughness, or excessively high cost. In the present study, porous silver was fabricated by Gasar process in pure oxygen atmosphere. The effect of oxygen pressure on porosity, pore nucleation, pore size and distribution were investigated. Up to now, most of the researches on lotus type porous material are based on a metal-hydrogen system, like $\mathrm{Cu}-\mathrm{H}_{2}, \mathrm{Mg}-\mathrm{H}_{2}{ }^{[8-10]}$. However, the fabrication of lotus-type porous material by the Metal-Oxygen system has not been fully investigated. Oxygen is considered to be an ideal working gas for fabrication of lotus silver, because the oxygen solubility in silver is $2.17 \mathrm{~mL} / 100 \mathrm{~g}$ at melting point, which is much larger than that of hydrogen $(0.016 \mathrm{~mL} / 100 \mathrm{~g})$.

\section{Experiment}

The lotus-type porous silver was fabricated with the mold

\footnotetext{
Received date: October 12, 2015

Foundation item: National Natural Science Foundation of China (51164018)

Corresponding author: Jin Qinglin, Ph. D., Professor, School of Materials Science and Engineering, Kunming University of Science and Technology, Kunming 650093, P. R. China, E-mail: jinqinglin@yahoo.com 
casting technique. The schematic drawing of the apparatus is shown in Fig 1. The apparatus consists of melting part, casting part and mold part with water cooled copper plate, both of which are installed in a high pressure chamber. High purity silver (99.99\%) was melted in the crucible by radio-frequency heating under high pressure gas of purity oxygen from $0.2 \mathrm{MPa}$ to $0.5 \mathrm{MPa}$. After silver was completely melted, silver the pressurized condition was maintained for $600 \mathrm{~s}$ in order to make oxygen dissolve in the molten. Thus, oxygen was dissolved uniformly into the molten silver to the equilibrium concentration according to the Sievert's law in the oxygen atmosphere. Then, the melt was poured into the mold whose bottom plate was cooled down with water circulated through a chiller by rotating the chamber by $90^{\circ}$. During the solidification, oxygen in the melt was rejected at the solid-liquid interface due to the solubility gap of oxygen between in the liquid and in the solid and formed cylindrical pores that were aligned parallel to the solidification direction. The dimensions of the resulting ingot were about $60 \mathrm{~mm}$ in diameter and 80 $\mathrm{mm}$ in height.

Overall porosity (ingot porosity), $\varepsilon$, was evaluated using the following expression:

$$
\varepsilon=\left(1-\rho / \rho_{0}\right) \times 100 \%
$$

where, $\rho$ and $\rho_{0}$ are apparent density of porous silver and bulk silver, respectively. The former was estimated by Archimedes method. The porous silver ingots were cut in halves with a spark erosion wire cutter in order to observe the structure of the cross sectional plane parallel to the solidification direction. Then the half pieces were cut perpendicularly to the solidification direction at the position of 5, 20, 40 and $60 \mathrm{~mm}$ from the bottom plan. In order to determine the porosity, values of diameter and area of pores, each cross section perpendicularly to the solidification direction was analyzed using image-J processing program.

\section{Results and Discussion}

\subsection{Pore morphology}

Fig.2a 2f show optical micrographs of the pore morphology of lotus-type silver, which are the cross sections perpendicular to and parallel to the solidification direction under different oxygen pressures. The pores in the cross section perpendicular to the solidification direction are nearly round, while those parallel to the solidification direction are long and grow to the solidification direction. However, it can be seen from Fig.2d 2f that the $1 / d$ (pore aspect ratio) is much less than that in lotus copper ${ }^{[11]}$ or magnesium ${ }^{[12]}$ fabricated in hydrogen atmosphere. This is associated with the different diffusion behavior between oxygen and hydrogen in liquid metal.

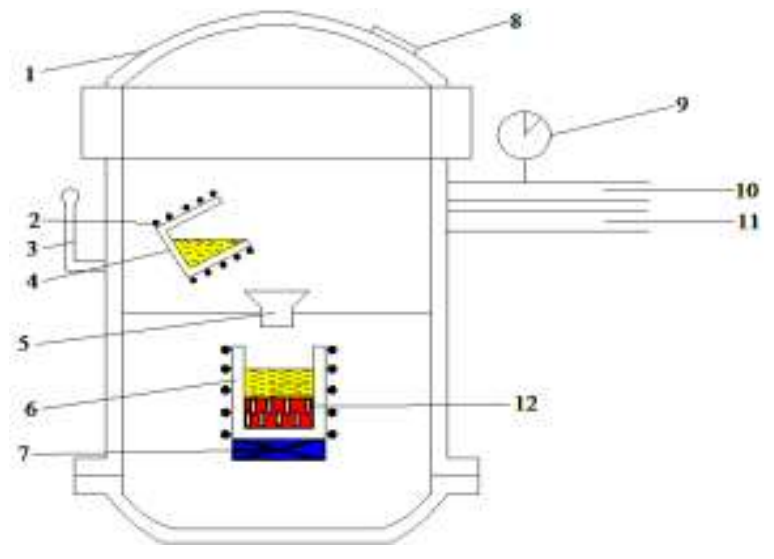

1. high pressure chamber; 2 . induction heating coil; 3 . control lever; 4. melting crucible; 5. graphite funnel; 6. casting crucible; 7. water cooled copper chiller; 8 . observation window; 9. pressure gauge; 10 . inlet of gases; 11 . outlet of gases; 12. lotus-type porous materials

Fig.1 Schematic drawing of the fabrication apparatus for lotustype porous material

\subsection{Porosity}

The porosity was evaluated on the basis of the idea that the gas pores are formed by the insoluble oxygen during solidification of the liquid silver dissolving oxygen.

Fig.3 shows the oxygen pressure dependence of the porosity of lotus-type porous silver. The porosity was determined through Eq. (1) from the apparent density of the porous silver. The porosity increases with increasing pure oxygen pressure.

In Gasar solidification in Fig.4 the formation of lotus-type porous structure depends on whether the bubbles of nucleation grow together with solid phase in the solidification interface ${ }^{[13]}$. Solidification cooling can make supersaturation of dissolved in the melt very big, and lead to bubbles nucleation before melt solidification. When the bubbles floating rate $V_{\mathrm{p}}$ is more than solidification velocity $V_{\mathrm{s}}$, bubbles can float from melt. In the present work, solidification velocity $V_{\mathrm{s}}$ is constant. When Reynolds number $R \mathrm{e}<2$, the bubbles floating rate $V_{\mathrm{p}}$ can be determined by Stoke law ${ }^{[14]}$,

$$
V_{\mathrm{P}}=\frac{2 r^{2} \mathrm{~g}\left(\rho_{\mathrm{L}}-\rho_{\mathrm{G}}\right)}{9 \eta}
$$

where, $r$ and $\rho_{\mathrm{L}}$ are bubble radius and liquid density, respectively. $\eta$ and $\rho_{\mathrm{G}}$ are liquid viscosity and gas density, respectively. $\rho_{\mathrm{G}}$ follows the ideal gas law,

$$
\rho_{\mathrm{G}}=\frac{P_{\mathrm{b}} M_{\mathrm{O}_{2}}}{R_{\mathrm{g}} T_{\mathrm{m}}}
$$




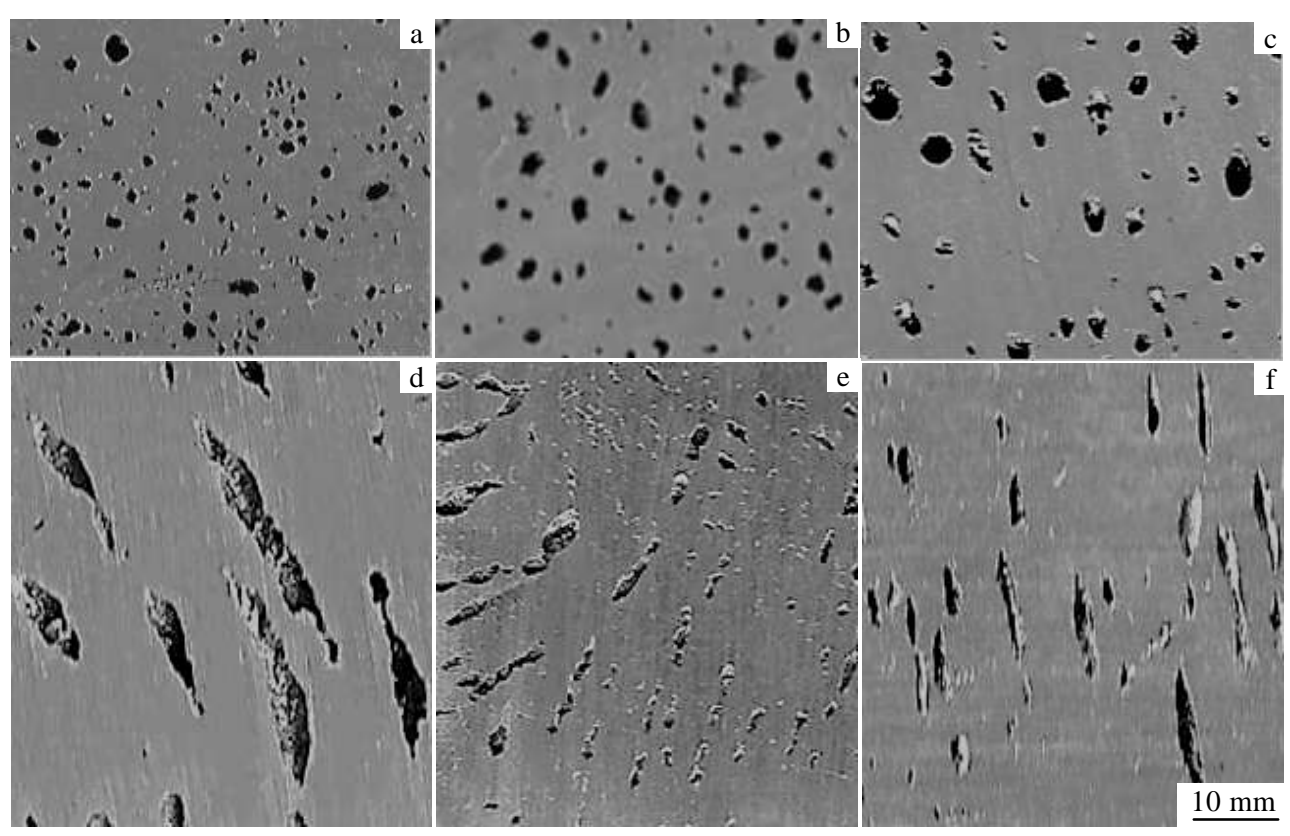

Fig.2 Cross sections perpendicular $(\mathrm{a} \sim \mathrm{c})$ and parallel $(\mathrm{d} \sim \mathrm{f})$ to the solidification direction of the lotus-type silver fabricated under oxygen atmosphere 0.3 MPa (a, d), 0.4 MPa (b, e), and 0.5 MPa (c, f)

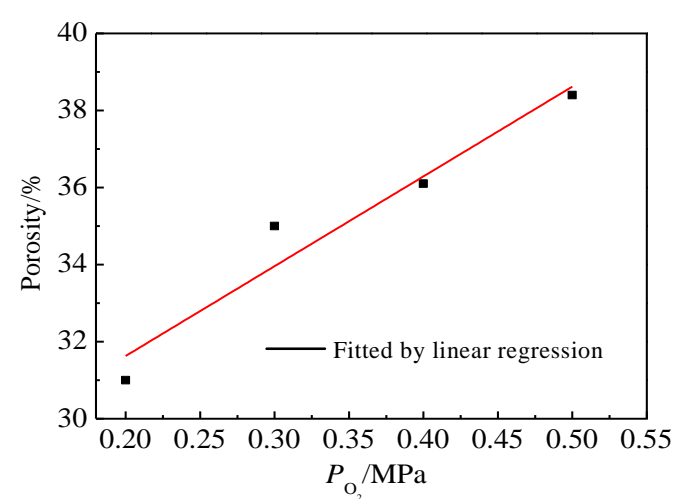

Fig.3 Porosity of lotus-type porous silver as a function of oxygen pressure

where, $P_{\mathrm{b}}$ is oxygen pressure inside bubbles and $M_{\mathrm{O}_{2}}$ is the molecular weight of oxygen. $R_{\mathrm{g}}$ and $T_{\mathrm{m}}$ are the ideal gas constant $(8.314 \mathrm{~J} / \mathrm{mol} \cdot \mathrm{K})$ and metal melting point $(1234 \mathrm{~K})$, respectively. $P_{\mathrm{b}}$ can be expressed as:

$$
P_{\mathrm{b}}=P_{\mathrm{O}_{2}}+\rho_{\mathrm{L}} g h+\frac{2 \sigma_{\mathrm{LG}}}{r}
$$

where, $\rho_{\mathrm{L}}$ is liquid density and $h$ is the depth of bubbles in the melt. $\sigma_{\mathrm{LG}}$ and $r$ are interface energy of liquid/gas and bubbles radius, respectively. $g$ is $9.8 \mathrm{~m} / \mathrm{s}^{2}$.

Gasar solidification can be regarded as a heat transfer problem in one dimensional direction. In the condition of heat balance, heat conduction equation can be expressed as ${ }^{[15]}$ :

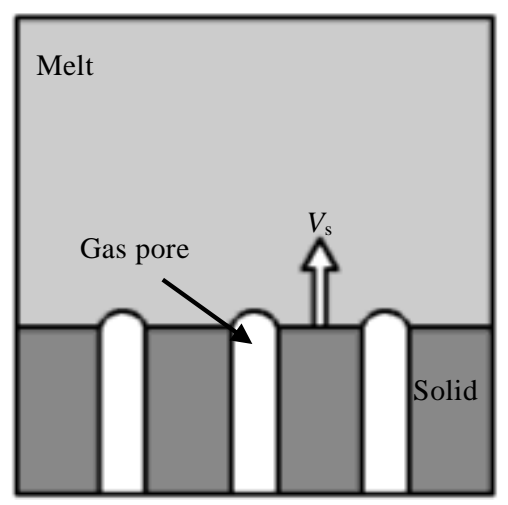

Fig.4 Schematic diagram for metal-gas eutectic unidirectional solidification

$$
\lambda_{\mathrm{S}} G_{\mathrm{S}}-\lambda_{\mathrm{L}} G_{\mathrm{L}}=\rho_{\mathrm{S}} L_{\mathrm{m}} V_{\mathrm{S}}
$$

where, $\lambda_{\mathrm{S}}$ is solid thermal conductivity and $\lambda_{\mathrm{L}}$ is liquid thermal conductivity, respectively. $G_{\mathrm{S}}$ and $G_{\mathrm{L}}$ are temperature gradient of solid phase and gradient of liquid phase, respectively. $\rho_{\mathrm{S}}$ and $L_{\mathrm{m}}$ are solid density and latent heat of crystallization, respectively. $V_{\mathrm{S}}$ is solidification velocity.

According to the related parameters in Ref.[16], calculation result of solidification velocity $V_{\mathrm{S}}$ is $11.21 \mathrm{~mm} / \mathrm{s}$ at the melting point. We insert solidification velocity $V_{\mathrm{S}}$ in Eq.(2), and then we can get the relationship between critical radius of floating bubble and oxygen pressure in Fig.5. 


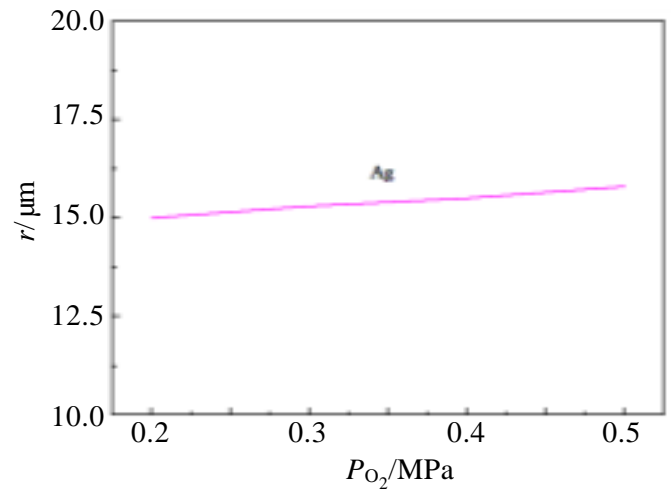

Fig.5 Relationship between the critical radius of bubble and the pressure

Critical radius of floating bubble increases slightly with the increasing pressure of oxygen. According to Eq.(2), (3), and (4), the bubble floating rate $V_{\mathrm{p}}$ increases with the increasing pressure of oxygen. Imagine the solidification is in steady state, the solidification velocity $V_{\mathrm{s}}$ is constant. An increased bubbles floating rate $V_{\mathrm{p}}$ will result in an increased oxygen content of solid/liquid interface. Meanwhile, the solidification velocity $V_{\mathrm{s}}$ is much larger than bubbles floating rate $V_{\mathrm{p}}$. Thus it is considered that the porosity increases with the increasing pressure of oxygen.

\subsection{Average pore diameter}

Fig.6 shows the oxygen pressure dependence of the average pore diameter of lotus-type porous silver in the cross section on the sample plane, which was determined by the microstructure analysis. The average pore diameter decreases with increasing the oxygen pressure.

According to the nucleation theory by Fisher ${ }^{[17,18]}$, when the pores are formed in the liquid phase during solidification by homogeneous nucleation, the gas pressure required for the pore nucleation is evaluated to be a few GPa. This magnitude of the pressure is not realistic. Therefore, the pores are considered to nucleate heterogeneously. According to the study of $\operatorname{Park}^{[18]}$, he suggested the following relationship between the pore nucleation rate $I$ and oxygen pressure $P_{\mathrm{O}_{2}}$ for heterogeneous pore nucleation:

$$
I=\frac{N k T}{h} \exp \left[-\frac{16 \pi}{3 \mathrm{k} T} \cdot \frac{\sigma}{\Delta P^{2}} f(\theta)\right]
$$

where, $N$ is the number of atoms in the liquid, $k$ is Boltzmann's constant, $T$ is the temperature, $h$ is Planck's constant, $\sigma$ is the surface energy of the pore, $\Delta P$ is the difference between the ambient and the internal pressure of the pore and $f(\theta)$ is a function of the surface energy that depends on the contact angle $\theta$ between the solid and the pore.

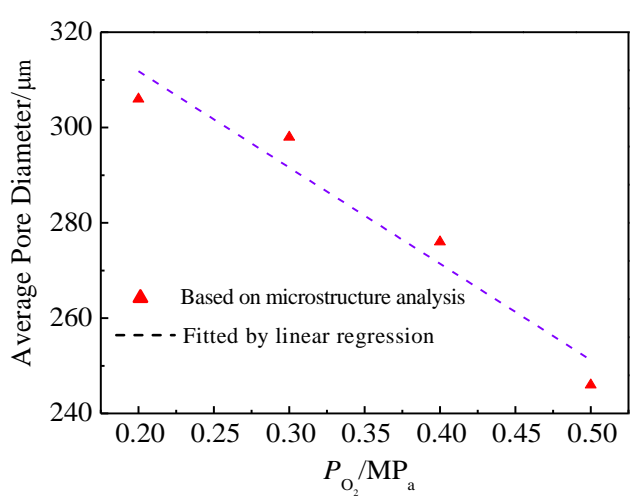

Fig.6 Average pore diameter of lotus-type porous silver as a function of oxygen pressure

In Eq.(6), the pore nucleation rate $I$ is closely related to $\Delta P$. With increasing of the oxygen gas pressure, $\Delta P$ and the pore nucleation rate $I$ to rise correspondingly. Under the condition of certain superheat and oxygen pressure, the content of oxygen in solid/liquid interface is constant. With increasing of the pore nucleation rate $I$, the oxygen diffused in each pore quantity will decrease, Thus it is considered that the average pore diameter decreases with increasing pressure of oxygen.

\section{Conclusions}

1) The lotus-type porous silver with cylindrical pores can be fabricated by Gasar process in oxygen atmosphere.

2) The cylindrical pores are formed at the solid-liquid interface due to difference of oxygen solubilities between solid and liquid phase. The porosity of $35 \%$ increases to $38.4 \%$ with increasing pressure of oxygen from $0.2 \mathrm{MPa}$ to $0.5 \mathrm{MPa}$. Average pore diameter decreases with increasing pressure of oxygen. It is concluded that the pore evolution is attributed to the precipitation of the super-saturated oxygen in the solidified silver through melt.

Acknowledgment: Thanks to the support of the MSIP (Ministry of Science, ICT \& Future Planning) of Korea; and the fund of the State Key Laboratory of Advanced Technologies for Comprehensive Utilization of Platinum Metals.

\section{References}

1 Banhart J. Prog Mater Sci[J], 2001, 46: 559

2 Shapovalov V I. US Patent, 5181549[P]. 1993

3 Liu Y, Li Y X, Zhang H W et al. Acta Metallurgica Sinica[J], 2004, 40(11): 1121 (in Chinese)

4 Xie J X, Liu X H, Liu X F et al. The Chinese Journal of Nonferrous Metals[J], 2005,15(11): 1869 (in Chinese)

5 Hyun S K, Nakajima H. Materials Science and Engineering[J], 2003, A340(1-2): 258 
6 Hyun S K, Nakajima H, Boyko L V et al. Materials Letters[J], 2004, 58(06): 1082

7 Li H F, Zhang X S, Lv L B et al. Electroplating \&Pollution Control[J], 2007, 27(02): 4

8 Liu P S. Introduction to Cellular Materials[M]. Beijing: Tsinghua University Press, 1999: 6

9 Yamamura S, Shiota Y, Murakami K et al. Mater Sci Eng A[J], 2001, 318: 137

10 Xie Z, Ikeda T, Okuda Y et al. Japanese Journal of Applied Physics[J], 2004, 43(10R): 7315

11 Park J S, Hyun S K, Suzuki S et al. Acta Materialia[J], 2007, 55: 5646

12 Xie Z, Tane M, Hyun S et al. Materials Science and
Engineering $A[\mathrm{~J}], 2006,417(1): 129$

13 Nakajima H, Hyun S K, Ohashi K et al. Colloids Surf A[J], 2001, 179: 209

14 Li Z J, Jin Q L, Yang T W et al. Acta Metallurgica Sinica[J], 2013, 49(06): 757 (in Chinese)

15 Han Q Y. Kinetics of Metallurgical Process[M]. Beijing: Metallurgical Industry Press, 1983: 170 (in Chinese)

$16 \mathrm{Hu} \mathrm{H} \mathrm{Q.} \mathrm{Metal} \mathrm{Solidification} \mathrm{Principle[M].} \mathrm{Beijing:} \mathrm{China}$ Machine Press, 2000 (in Chinese)

17 Yang T W, Li Z J. Foundry Technology[J], 2013, 34(2): 174 (in Chinese)

18 Fisher J C. J Appl Phys[J], 1948, 19: 1062

\title{
纯氧分压 Gasar 工艺下藕状多孔银的气孔结构研究
}

\author{
梁 娟 ${ }^{1}$, 金青林 ${ }^{1}$, 杨天武 ${ }^{1}$, 李再久 ${ }^{2}$, 谢 明 $^{2}$ \\ (1. 昆明理工大学, 云南 昆明 650093) \\ (2. 昆明贵金属研究所, 云南 昆明 650106)
}

\begin{abstract}
摘 要: 金属-气体共晶定向凝固（Gasar）是制备藕状多孔金属的新工艺, 利用自行研制的 Gasar 装置, 制备了不同纯氧分压下的藕状 多孔银试样, 研究了氧气分压对藕状多孔银气孔形貌 (气孔率、气孔尺寸和分布、气泡形核) 的影响。结果表明: 氧气分压对气孔形 貌影响十分显著。随着氧气压力的增加, 气孔率增大而平均气孔直径减小。
\end{abstract}

关键词: 藕状多孔; 共晶凝固; 多孔银; 氧; 气孔率

作者简介: 梁 娟, 女, 1989 年生, 硕士, 昆明理工大学材料科学与工程学院, 云南 昆明 650093, E-mail: 1005126385@qq.com 